\title{
Revealing the Story of an Individual through Narrative Inquiry : A Methodological Review
}

\author{
Surya Prasad Adhikari \\ suryapdad@gmail.com \\ Lecturer \\ Central Department of Education, T.U., Kirtipur
}

\begin{abstract}
In this paper I have discussed about the narrative inquiry research design. The story of the participant is collected by the researcher through inquiry. The story is re-storied by the researcher and finally revealed. A good bond should be made between the researcher and participant(s) in order to gather required amount of data. The aim of my article is to find out the way of revealing individual stories by using narrative research design. I have used secondary data from books, articles, and dissertations as a methodological review. From the methodological review the sample size for narrative research design is flexible, where there can be participation of one to twenty five participants. Arigorous interview with the participants should be taken one to three times or until the saturation of data. Typically, one to two cases can be observed while developing the story from the narrative inquiry. Similarly, methods of data collection are: interview, observation, focus group discussion for direct study of participants. Data collection tools used are: interview guideline, structured, semi-structured, and unstructured questionnaires, observations schedule, documentation of participation, and transcripts. The researcher develops the "codes" from the interview text or interview transcript, "categories" the codes in related groups and finally develops the "themes" from the categories which relate to the objectives and research questions. Ethical consideration is necessary for the secrecy of participants as the norms of qualitative research and trustworthiness is also the must for the validation of data.
\end{abstract}

Keywords: Narrative inquiry, Qualitative research design, Experiences, Reveals, Methodology

\section{Introduction}

I enrolled the Master in Philosophy (MPhil) leading to the Philosophy in Degree (Ph.D.) program in the Graduate School of Education, TU in 2017 A.D. Two of my professors taught me qualitative research. I really enjoyed their classes and have now decided to choose a narrative research design for my Ph.D. study. I reviewed some articles, books, and Ph.D. dissertations regarding the narrative inquiry and was interested on this method of research. So, I decided to pursue narrative inquiry research design for my $\mathrm{PhD}$ study. My $\mathrm{PhD}$ supervisor stated me that deep narration was 
really challenging since all the information may not be acquired easily and not even in a single meeting with the narrator. So, a good bond between the researcher and the participant should be built and narrative interview should be taken artistically. Such difficulties were mentioned in many literature reviews of many scholars and I faced the same during narrative interview. So, I decided to write an article in order to provide with an easy understanding and guidance on using narrative research design by using methodological review. The main aim of this article is to clarify on the doubts that may arise during narrative research design and, to provide better understanding on its methodological and analytical section.

Narrative inquiry is famous in social science. According to (Connelly \& Clandinin, 1990) narrative inquiry is increasingly used in studies of educational experience (p.2). This is a rigorous research methodology in which the researcher has to visit their participant's time and often in order to extract the information. Narrative inquiry explores the lived experience (Kim, 2016). Narrative inquiry helps in exchange of ideas and learning with each other. (Webster \& Mertova, 2007b) stated that 'narrative inquiry is a set of human stories' (p. 3). The story is told by the participant to the researcher. The researcher retells the participant's stories by embedding their ideas and finally reveals the story. In this way, the narrative research design is prepared based on themes generated from the stories. The narrative research design is a phenomenon to understand the multidimensional meaning of society, culture, human action, and life (Kim, 2016). Different themes can be generated based on such a multidimensional society, culture, occupations and professions which is finally incorporated in a single story. Likewise, (Connelly \& Clandinin, 1990) stated that narrative is a phenomenon studied in inquiry, the study of experience as a story, and as a methodology entails a view of the phenomenon (p.7 ). Narrative inquiry is a lived phenomenon of participants. Wang and Geale (2015) mentioned that narrative inquiry is not simply storytelling; it is a method of inquiry that uses storytelling to uncover nuance. Stories heal and soothe the body and spirit, provide hope and courage to explore and grow (p.198). Narrative inquiry is a process in which good intimacy between the researcher and participant is created in order to reveal their story.

An individual may feel difficulty in exploring their personal, occupational, and professional experiences of their life from which s/he got power and pain. However, the gain of power can be shared but pain may not. Researcher should create an environment to ease their participants to express their pain.

\section{The purpose}

The purpose of the study is to explore the way of revealing individual stories about life experiences regarding any personal, occupational, and professional issues by using narrative research design. 


\section{Conceptual framework}

The following conceptual framework guided me to write this article:

Figure: 1 Conceptual framework of the study

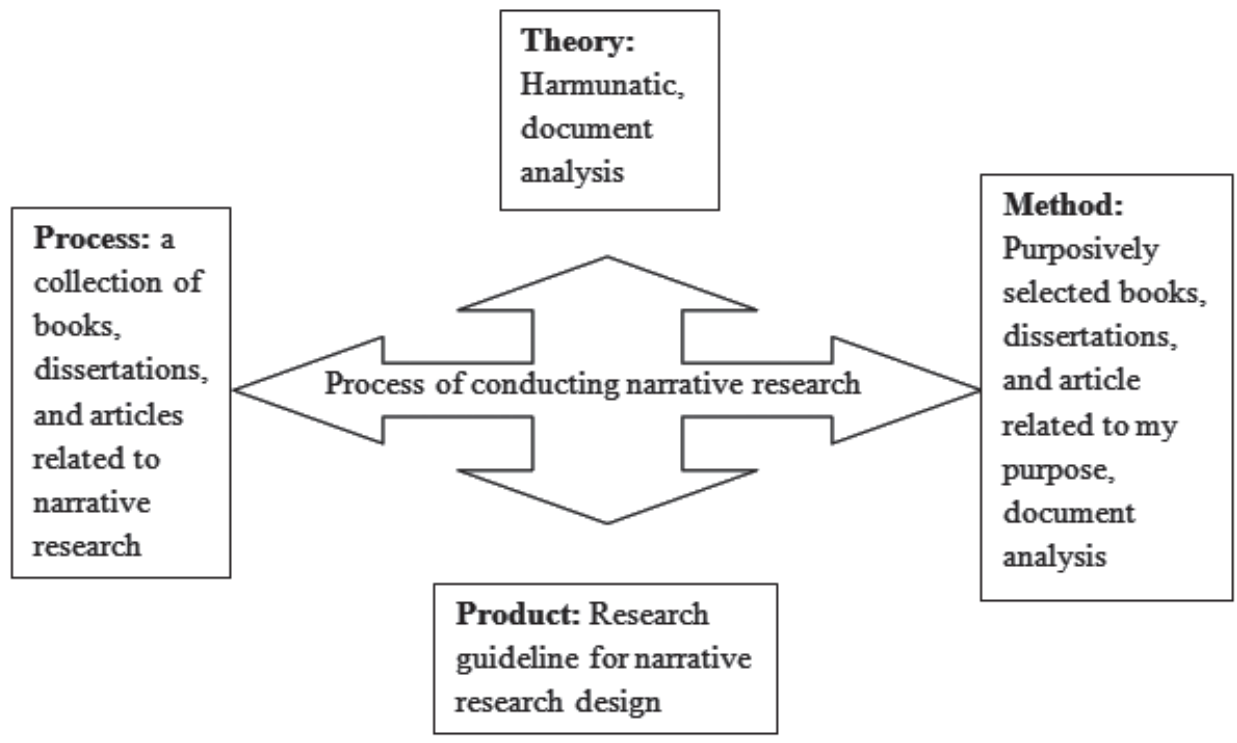

Different books, dissertations, and articles related to narrative research were reviewed in detail. A good frame for using narrative inquiry as research design was developed during this methodological review. Various ideas regarding sample size, data collection process, interview frequency, and situation were generated during the review. These ideas are studied and a clear guideline to conduct are search by using narrative research design is presented in this research paper.

\section{Methodology}

This study is based on secondary sources of data. Narrative research related books, articles, and dissertations are reviewed which were already collected during my $\mathrm{PhD}$ journey.

The study is based on thematic and descriptive approach to narrative writing. The themes of this study are mostly based on different components of the research paper. This article is developed by going thoroughly on different documents written by the scholars on narrative research design. I also solved the confusions that may arrive to the future researcher when using the narrative research design. 


\section{Methodological framework}

The following methodological framework guided me to write this article:

Figure: 2 Methodological framework of the study

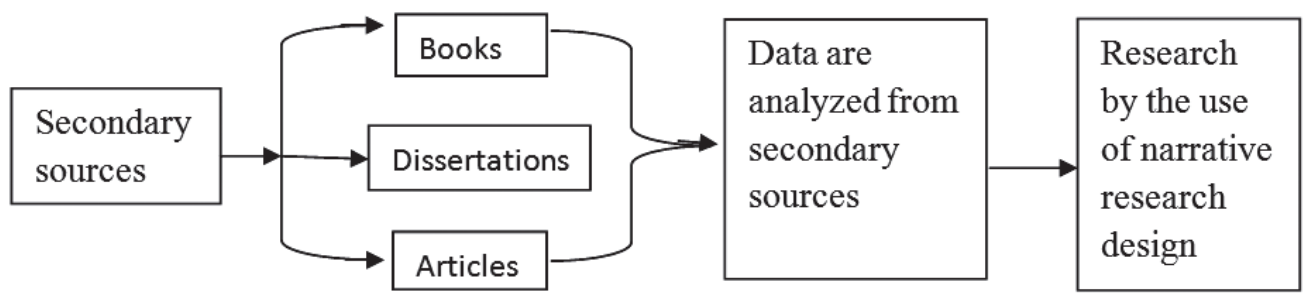

This article is based on review of the documents related to the narrative inquiry. Books, dissertations and articles are reviewed to complete this paper. Similarly, these information or documents are analyzed and the process of research by using the narrative inquiry design is revealed.

\section{Result and Discussion}

This study discusses on the way of using narrative research design in an effective way to conduct a research. After review of the narrative research, I made themes from the components of the introduction, methodology, and analysis sections of the research. The themes of the study are discussed the following subheadings.

\section{Statement of Problems in Qualitative Research}

While writing this section of the study the reason of motivation of the researcher to choose this specific area/title of the research should be clarified. The central idea like purpose, intent or objective of every research is incorporated in the statement of problem section of research. Creswell (2007) focus on a single phenomenon (key concept or idea). The main objective of research is clear in the statement of problem section. According to (Creswell, 2007), the interrelationship between design and approach continues with the purpose statement, a statement that provides the major objective or intent, or "road map," to the study (p.103). The purpose statement is the most important statement in an entire research study. It orients the reader to the central intent of the study and establishes the direction for the research. The purpose statement needs to be written as clearly and concisely as possible. This entire section focuses on the purpose statement because of its significance in study.

\section{Objectives and Research Questionnaire in Narrative Inquiry}

The title of narrative inquiry is different than the other research design and methodology. The title is related to personal, occupational, and professional experiences. Similarly, objectives and research questionnaires are also related to personal, occupational, and professional experiences. The personal story is revealed by the researcher. The researchers are generating the narrative of narrator's life in the social world. Narrators have their own narrative in their lives. Through the story of narrator,researchers get the story of human life through the language. Arguments of narrator life are present and published by the researcher. There can be a single objective 
or research question may be in the narrative research and more. The research title reflects the objective or research question.

\section{Sample, Sampling, and Saturation}

Regarding the research participants Beitin (2012) stated that the sample size can be ranged from 6 to 12 participants (as cited in(Kim, 2016).Similarly, Cresewell (2013)states that "narrative research is best for capturing the detailed stories or life of a single individual or the lives of a small number of individuals" (pp. 73-74).In this regard, Eikeland (2018)collected inquiries from 12 teachers to study "The life world of Nepalese teachers" by using narrative research design in her $\mathrm{PhD}$ dissertation. The adequate number of sampling is not determined solely but by the suitability of the information or data. Depth and breadth of information to be achieved until the saturation of data is taken from the participants (Kim, 2016). Likewise, Creswell (2007) states that in a narrative study, the researcher reflects more on who to sample the individual may be convenient to study because she or he is available, a politically important individual who attracts attention or is marginalized, or atypical, ordinary person. Regarding the number of the interview around five to twenty five, based on the combination of time and resources available but minimum of three round of in-depth life story interview is required for a narrative interview (Kvale, 1996 as cited in (Kim, 2016). Creswell (2007) states that all of the individuals need to have stories to tell about their life experiences. Inquirers may select several options, depending on whether the person is marginal, great, or ordinary. In this study, I selected published articles books and dissertation. This number would be adequate to yield sufficient depth.

Topology of sampling is mentioned below:

Table 1 Typology of sampling strategies in qualitative inquiry

\begin{tabular}{|l|l|}
\hline Type of Sampling & Purpose \\
\hline Maximum variation & Documents diverse variations and identifies important common patterns \\
\hline Homogeneous & Focuses on reduce, simplifies, and facilitates group interviewing \\
\hline Critical case & Permits logical generalization and maximum application of information to other cases \\
\hline Theory-based & Find examples of a theoretical construct and thereby elaborate on and examine it \\
\hline $\begin{array}{l}\text { Confirming and } \\
\text { disconfirming cases }\end{array}$ & Elaborate on initial analysis, seek exceptions, looking for variation \\
\hline Snowball or chain & $\begin{array}{l}\text { Identifies cases of interest from people who know people who know what cases } \\
\text { are information-rich }\end{array}$ \\
\hline Extreme or deviant case & Learn from highly unusual manifestations of the phenomenon of interest \\
\hline Typical case & Highlights what is normal or average \\
\hline Intensity & $\begin{array}{l}\text { Information-rich cases that manifest the phenomenon intensely but not } \\
\text { extremely }\end{array}$ \\
\hline Politically important & Attracts desired attention or avoids attracting undesired attention \\
\hline Random purposeful & Adds credibility to sample when the potential purposeful sample is too large \\
\hline Stratified purposeful & Illustrates subgroups and facilitates comparisons \\
\hline Criterion & All cases that meet some criterion; useful for quality assurance \\
\hline Opportunistic & Follow new leads; taking advantage of the unexpected \\
\hline Combination or mixed & Triangulation, flexibility; meets multiple interests and needs \\
\hline Convenience & Saves time, money, and effort, but at the expense of information and credibility \\
\hline
\end{tabular}

Source: Miles \& Huberman, 1994 
Regarding observation Cresewell (2013) suggested that observation of one to two cases which he observed unless a collective story is developed for the narrative approaches. He provided observations and some recommendations of sample size that ranges for the narrative inquiry approaches; narrative inquiry and one to two cases observed unless developing a collective story. According to (Guest, Bunce, \& Johnson, 2006) Suggested that theoretical saturation is the point where the qualitative analyst does not see any new information in the data related to the themes, codes, or theory.

\section{Source of Data}

In this article, I have used only the secondary source of data as a methodological review to my research purpose. The narrative can be taken from the participants as primary and secondary sources of data. Data needs to be supported by the secondary sources or documents. Clandinin and Connelly (2000)suggest that the collecting field texts through a wide array of sources, autobiography, journal, researcher field notes, letters, conversations, interviews, stories of families, documents, photographs, and personal-family social artifacts (as cited in (Creswell, 2007).According to Connelly and Clandinin (1990)data can be in the form of field notes of the shared experience, journal records, storytelling, letter writing, other's observations, interview transcripts, autobiographical writing, documents such as class plans and newsletters, principles, personal philosophies writing such as pictures, rules, and metaphors.

\section{Research Methods}

This narrative study explored participant's narrative from the different methods and tools.

\section{Tools}

Narrative inquiry tools are survey, interview, observations, documentation, and transcripts (Webster \& Mertova, 2007a). The researcher takes an interview of the participant's past, present and future. Here, I have discussed about only interview and observation.

\section{Interview}

A narrative interview is a method of data collection. There are three types of narrative interview questionnaire tools; structured, semi-structured, and unstructured for qualitative research. Most commonly used data collection method in qualitative research and the foremost method in narrative inquiry in particular is the individual interviews (Kim, 2016). For a successful interview, good preparation is necessary. Interview questionnaires or guidelines are tools for data collection. Similarly,Connelly and Clandinin (1990) state that the data collection tool in narrative inquiry is the unstructured interview (p.5). The researcher can choose any of these categories is based on their choice. Guetterman (2015) concluded that researchers typically conducted one interview per person and maximum number of interviews per person is four in qualitative approaches.

The narrative interview questionnaires are six to ten in numbers(Kim, 2016). One questionnaire is connected to the other. The connecting questionnaire asked for the fulfillment of objectives and research questionnaires. The narrative interview questionnaires are related to the participant's biographical study, autobiographical, life history, and oral history (Kim, 2016), (Cresewell, 2013) 
and (Creswell, 2007). Narrative research design focuses on interviewing a person, collecting information from stories, reporting experiences, and drawing the meaning of those experiences for the individual (Cresewell, 2013). According to Chase (Chase, 2005) the aim of an in-depth interview is specifically to transform the interviewer relationship into either narrator or listener.

Data are collected by the interaction with participants. There are three methods of collecting narrative inquiry. The first is an "oral stories" from the presentation, conversations, and interviews which are finally transcript by the researcher. The second one is "written stories" from journals, diaries, letters, email, blogs, autobiographies, biographies, artwork, and photographs of an individual. These can be documents or artifact analysis. And the final one is "lived stories" from direct observations of participants, and interactions between the participant and the researcher. Lastly, the data are transcript by the researcher for storytelling and revealing the story of participants.

The narrative interview can be taken from three different questionnaire structure: structured, semi structured and unstructured. The number of interview questionnaire may be six to ten.

An interviewer with the participants arise two different types of social conditions, external and internal. External social conditions are related to the individual's culture, society, linguistic relationships, and interactions between individual and inquirer. Internal condition is related to an individual's conditions like feelings, desires, hopes, existential viewpoints, aesthetic reactions, and moral dispositions of the story's characters.

Table: 2 The interaction and continuity dimensional space narrative structure

\begin{tabular}{|c|c|c|c|c|c|}
\hline \multicolumn{2}{|c|}{ Interaction } & \multicolumn{4}{|c|}{ Continuity } \\
\hline Personal & Social & Past & Present & Future & Situation/place \\
\hline $\begin{array}{l}\text { Look inward } \\
\text { to internal } \\
\text { conditions, } \\
\text { feelings, } \\
\text { hopes, } \\
\text { aesthetic } \\
\text { reactions, } \\
\text { moral } \\
\text { dispositions }\end{array}$ & $\begin{array}{l}\text { Look outward } \\
\text { to existential } \\
\text { conditions in the } \\
\text { environment with } \\
\text { other people and } \\
\text { their intentions, } \\
\text { purposes, } \\
\text { assumptions, and } \\
\text { points of view }\end{array}$ & $\begin{array}{l}\text { Look } \\
\text { backward to } \\
\text { remembered } \\
\text { experiences, } \\
\text { feelings, and } \\
\text { stories from } \\
\text { earlier times }\end{array}$ & $\begin{array}{l}\text { Look at } \\
\text { current } \\
\text { experiences, } \\
\text { feelings, } \\
\text { and stories } \\
\text { relating to } \\
\text { actions of an } \\
\text { event }\end{array}$ & $\begin{array}{l}\text { Look } \\
\text { forward to } \\
\text { implied and } \\
\text { possible } \\
\text { experiences } \\
\text { and plot } \\
\text { lines }\end{array}$ & $\begin{array}{l}\text { Look at context, } \\
\text { time, and place } \\
\text { situated in a physical } \\
\text { landscape or setting } \\
\text { with topological and } \\
\text { spatial boundaries } \\
\text { with characters' } \\
\text { intentions, purposes, } \\
\text { and different points } \\
\text { of view }\end{array}$ \\
\hline
\end{tabular}

Source: Adapted from Clandinin and Connelly 2000 as cited in (Wang \& Geale, 2015p.197)

\section{Observation}

Observation is closely related to the role of the inquirer. Field notes of the participants are collected through observation (Creswell, 2007). An observation supports researcher's data skillfully. The researcher only observes the related field on which study should be carried out.(Kim, 2016) states that observational skills are visual thinking strategies which is utilized by the researcher very skillfully. According to (Connelly \& Clandinin, 1990) field records collected through participant observation in a shared practical setting is one of the primary tools of narrative inquiry work 
(p.5). Similarly, (Guetterman, 2015) concluded that in narrative inquiry, one to two cases are observed unless a collective story is developed. Observation is a primary tool used very carefully in which only the field related to the research are focused. These particular cases of participants are observed by the researcher and finally a well-constructed story is generated. An observation check list or a field note should be used to observe the participant activities in their working place for effective study.

\section{Analysis and Interpretation of Data}

The researcher needs to thoroughly study the field notes and transcripts time and again in order to analyze the data. The researcher then interprets and inspects the data more clearly and will excavate a meaningful story. The researcher filters the narrative data for analysis and interprets to find narrative meanings in the collected data (Kim, 2016). The following table discusses on the way of narrative data analysis and interpretation:

Table 3 Narrative data analysis and representation

\begin{tabular}{|l|l|}
\hline $\begin{array}{l}\text { Data } \\
\text { analysis and } \\
\text { Representation }\end{array}$ & \\
\hline Data managing & Create and organize files for data \\
\hline Read memoing & Read through text, make margin notes, form initial codes \\
\hline Describing & Describe the story or objective set of experiences and place it in a chronology \\
\hline Classifying & Identify stories, Locate epiphanies and identify contextual materials \\
\hline Interpreting & Interpret the larger meaning of the story \\
\hline $\begin{array}{l}\text { Representing, } \\
\text { visualizing }\end{array}$ & $\begin{array}{l}\text { Present narration focusing on processes, theories, and unique and general } \\
\text { features of the life }\end{array}$ \\
\hline
\end{tabular}

Source: Savin-Baden \& Niekerk, 2007

Regarding qualitative data analysis(Kim, 2016)stated that this can be done on the basis of four basic elements; codes (Identifying concepts from raw data through multiple coding processes), categories (Linking codes to create a unit or category), patterns (Identifying repeated units (a pattern from categories), and themes (Creating a theme that represents similar patterns) (p.189). Similarly, these basic elements can also be used in narrative research design.

The text segments of the transcripts are developed into codes which are categorized into different groups and finally developed into the themes Creswell (2007). Similarly, (Jennifer, 2001) mentioned that the data analysis process is done by firstly building basic themes on the basis of transcripts and 'organizing themes' on the basis of the basic themes, then finally the 'global themes' based on organizing themes.

From the above discussion, there are basically three steps for data analysis. Initially, codes are developed from the transcript which are then separated into different categories and finally themes from these categories are developed. Themes are developed to meet the objectives or research questions of the study. 
Revealing the Story of an Individual through Narrative Inquiry : ... / 79

\section{Ethical Considerations}

Ethics in narrative research is a set of responsibilities in human relationships: privacy, responsibilities for the dignity, and well-being of the participants. Those who respond to a researcher's invitation letter and express a willingness to participate in the study should be contacted before the interviews. The researcher should inform the potential participant of the study about duration, activities, location, and amount of time required for inquiry. Research should be taken further ahead only after providing all the information to their participants and inquiry should be started only after the consent of the participants. The activities like using audio recorder and keeping the story of the participants confidential also fall under the ethical consideration.

\section{Conclusion}

On the basis of the findings of the study it can be concluded that the narrative inquiry is a skillful way of research in which information is extracted from the story of participants in a proficient manner and is re-storied to expose it to the social world. Restoring the participants' story is very difficult since the research ethics should be maintained. The researcher establishes such a friendly environment with their participants so that they feel free to share their stories to the researcher. There have been limited texts providing overview of narrative inquiry research design. This paper focuses on specific issues within narrative research design including introduction, methodology, and analysis. This paper provides starting guideline for new researchers unfamiliar with the narrative research design. There are potential challenges in the using this research design in title of the research, writing objectives, research questions, to the methodological components and analysis part. I hope this paper encourages the researcher to undertake narrative inquiry research design method studies. This paper is addressing the process of writing statement of the problem, objectives and research writing process in introduction part of the research. Similarly, selection appropriate sample size, suitable tools for data collection, frequency of interview, range or time of interview are mentioned. Finally, the analysis guideline is also provided in this paper which make the clear idea for the narrative research design user.

\section{References}

Chase, S. E. (2005). Narrative inquiry: Multiple lenses, approaches, voices. In N. K. Denzin \& Y. S. Lincoln (Eds.), The Sage handbook of qualitative research (3 ed., pp. 651-680). Thousand Oaks: Sage publication, Inc.

Clandinin, D. J., \& Connelly, F. M. (2000). Narrative inquiry: Experience and story in qualitative research.

Connelly, F. M., \& Clandinin, D. J. (1990). Stories of experience and narrative inquiry. Educational researcher, 19(5), 2-14. Retrieved from http://www.jstor.org/stable/1176100

Cresewell, J. W. (2013). Qualitative inquiry and research design: Chosing among five approaches. New Delhi: Aage

Creswell, J. W. (2007). Qualitative inquiry \& research design choosing among five approaches (2 ed.). London: Sage Publications. 
Eikeland, H. V. (2018). The life world of Nepalese teachers. (Doctoral Dissertation). University of Agder, Faculty of Humanities and Education, Oslo.

Guest, G., Bunce, A., \& Johnson, L. (2006). How many interviews are enough? : An experiment with data saturation and variability. Field method, 59 -82. doi:DOI: $10.1177 / 1525822 \times 05279903$

Guetterman, T. (2015). Descriptions of sampling practices within five approaches to qualitative research in education and the health sciences. Educational psychology papers and publications, 16(2). Retrieved from https://digitalcommons.unl.edu/cgi/viewcontent.cg i? article $=1275 \&$ context $=$ edpsychpapers

Jennifer, A. S. (2001). Thematic networks: an analytic tool for qualitative research. Qualitative research, 1(3), 385-405.

Kim, J.-H. (2016). Understanding narrative inquiry. London: Sage.

Miles, M. B., \& Huberman, A. M. (1994). Huberman source book qualitative data analysis: An expanded (2 Ed.). London: Sage Publication.

Savin-Baden, M., \& Niekerk, L. V. (2007). Narrative inquiry: Theory and practice. Journal of geography in higher education, 31(3), 459-472.

Wang, C. C., \& Geale, S. K. (2015). The power of story: Narrative inquiry as a methodology in nursing research. International journal of nursing sciences, 2(2), 195-198.

Webster, L., \& Mertova, P. (2007a). Using narrative inquiry as a research method: An introduction to using critical event narrative analysis in research on learning and teaching. London: Routledge.

Webster, L., \& Mertova, P. (2007b). Using narrative inquiry as a research method: An introduction to using critical event narrative analysis in research on learning and teaching. London: Routledge. 